\title{
Migration patterns of Thomson's gazelles and cheetahs on the Serengeti Plains
}

S. M. DURANT*, T. M. CARO $\ddagger^{\prime}$, D. A. COLlinS $\uparrow \S$, R. M. ALAWI $\dagger$, C. D. FITZGIBBON $\dagger^{\circ} *$ Department of Applied Biology, University of Cambridge, Pembroke Street, Cambridge CB2 OES, U.K.; †Serengeti Wildlife Research Institute, P.O. Box 661, Arusha, Tanzania; $\ddagger$ Evolution and Human Behavior Program, Rackham Building, University of Michigan, Ann Arbor, MI 48109-1070, U.S.A.; \$Department of Zoology, University of Edinburgh, West Mains Road, Edinburgh EH9 3JT, U.K.; ${ }^{\circ}$ Sub-Department of Animal Behaviour, University of Cambridge, Madingley, Cambridge CB3 8AA, U.K.

\section{Summary}

Monthly changes in abundance of Thomson's gazelles at 142 locations on the Serengeti Plains are presented over a $3 \frac{1}{2}$ year period. Numbers of gazelles on the eastern plains were strongly correlated with rainfall, whereas numbers in the central and western plains appeared to be related to other variables. Movements of female cheetahs and non-resident male cheetahs corresponded closely to the movements of Thomson's gazelles but those of resident male cheetahs remained relatively independent of the gazelle migration.

\section{Résumé}

Pendant 3 ans $\frac{1}{2}$, on a relevé les variations mensuelles de l'abondance des gazelles de Thomson à 142 points des plaines du Serengeti. Dans les plaines de l'Est, le nombre de gazelles est étroitement lié aux chutes de pluie alors qu'au Centre et à l'Ouest, il semble dépendre d'autres facteurs. Les mouvements des guépards femelles et aussi des guépards mâles non liés à un territoire correspondent étroitement à ceux des gazelles de Thomson mais ceux des guépards mâles territorialisés restent relativement indépendants de la migration des gazelles.

\section{Introduction}

The movements and censusing of ungulates in the Serengeti National Park, Tanzania have been the subject of intensive research for a number of years (e.g. Grzimek \& Grzimek, 1960; Sinclair and Norton-Griffiths, 1982; Borner et al., 1987). Out of convenience most of the work has been conducted from light aircraft, an appropriate method for estimating numbers of animals (Norton-Griffiths, 1978) but, unfortunately, it reduces the resolution with which animal movements can be monitored. Consequently description and causes of animal migrations, now a disappearing phenomenon in Africa due to the pressure of an increasing human population, are not well understood at a detailed level of analysis. In this paper, we 
document, on a monthly basis, the annual migration of one of the Serengeti's most numerous migratory ungulates, Thomson's gazelle, Gazella thomsoni (Günther), on the Serengeti Plains. These data are then used to examine the differential importance of rainfall in determining Thomson's gazelle distribution on the plains and its woodland border. They are important because they provide precise information about changes in gazelle concentrations relevant to the study of grasslandherbivore dynamics and predator-prey relations.

The detailed records also permit new examination of the relationship between prey and predator movements. Although it is known from many qualitative accounts that certain predators in Africa follow the movements of prey (e.g. spotted hyaenas Crocuta crocuta (Erxleben), Kruuk, 1972; brown hyaenas Hyaena brunnea (Thunberg), Mills \& Mills, 1982), it is difficult to demonstrate this phenomenon satisfactorily without the use of maps showing simultaneous location of predators and prey, which are rarely available. In the Serengeti, two species of predator, cheetahs, Acinonyx jubatus (Schreber), and hunting dogs, Lycaon pictus (Temminck), specialize in feeding on Thomson's gazelles (Kruuk \& Turner, 1967; Schaller, 1972), and might therefore be expected to follow closely the movements of this prey species. We shall present data on one of these predator species, the cheetah, whose diet has been reported as being made up of $90 \%$ Thomson's gazelles (Schaller, 1972). We show that the ranging of cheetah females, and of certain males, mirrors the migration patterns of Thomson's gazelles on the Serengeti plains.

\section{Methods}

\section{Counting numbers of Thomson's gazelles}

Thomson's gazelles were counted on 4379 occasions at 142 locations on the Serengeti Plains and plains-woodland border for a period of $3 \frac{1}{2}$ years from February 1982 to July 1985 (November and December 1984 excluded). Between November 1982 and January 1985 counts were systematic in that each of 122 points was visited once every month.

Using binoculars and standing on the bonnet of the vehicle, counts were made from specific locations, normally $4 \mathrm{~km}$ or more apart, on rises affording a good allround view of an area known to be utilized by Thomson's gazelles. Where possible, each location was visited every calendar month, and a minimum of 19 days was set between repeated observations at the same place. This was because it was found that gazelle numbers started to change appreciably after this period. At each location, the exact number of Thomson's gazelles counted within a $1 \mathrm{~km}$ radius was placed into one of eight categories: $0,1-10,11-50,51-100,101-200,201-500$, $501-1000,>1000$ in order to reduce errors that might arise from any inaccuracies in counting. Numbers rarely exceeded 2000 animals. Estimates of $1 \mathrm{~km}$ distance were calibrated and corrected regularly, and reliability in counting gazelles between different observers was high. For example, when TMC and two additional observers counted gazelles simultaneously, the number recorded was placed in the same category on $77.4 \%(n=106)$ and $83.7 \%(n=49)$ of occasions, and these observers never differed by more than one category.

A median category of gazelles was derived from counts made in different years for each calendar month and plotted on maps. Out of a total of 142 locations visited over the 12 months of the year there were 65 instances when only one count was 
taken for a particular month, 723 instances with two counts taken, 776 instances with three counts taken and 139 instances with four counts taken. One location was not visited at all in February. In some situations with two or four counts the median category was a fractional value. In these cases the lower intermediate figure was used in analysis ( 336 out of 1704 situations), thus there may have been a few cases in which gazelle categories were slightly underestimated.

The gazelle distribution was also plotted for wet season (November-May) and dry season (June-October) months to compare with seasonal cheetah movements. In this case a median category for any given location was obtained from all the monthly counts over all the years for that particular season.

\section{Rainfall records}

In the Serengeti, primary productivity of the habitat is largely determined by rainfall (Maddock, 1979), hence movements of gazelles might be expected to follow closely patterns of rainfall. Each month, thirty-one rain gauges on the plains were read by members of the Serengeti Wildlife Research Institute, and from August 1982 to January 1985 inclusive, Thomson's gazelles were counted from each rain gauge in the manner described above except that the observer (RMA) did not mount the bonnet of the vehicle. Categories of gazelles counted at each gauge were subsequently compared with the number of millimetres of rain measured there each month. At three gauges, 'Simba kopjes', 'Semetu kopjes' and 'Ndutu Lodge' (see legend of Fig. 3 for names), it was difficult to get a good view of the surrounding area, and so rainfall figures were correlated with the gazelles counted at the two nearest points (one point only at 'Ndutu Lodge'), even though data from which were not necessarily collected on the same day.

\section{Sightings of cheetahs}

During most of the days of the study, a prearranged region of the study area (see Fig. 3) was systematically searched for cheetahs, often in the course of censusing gazelles (by TMC, DAC and CDF). Sex, age, location and date were noted at each cheetah sighting between February 1982 and July 1985, and only the first sighting of any individual in the day was used in analysis (see Caro \& Collins, 1986, 1987a for details). Location of cheetah sightings were subsequently placed on a map divided into grid squares $(500 \mathrm{~m} \times 500 \mathrm{~m})$. Even if a number of sightings were made of the same or of different individuals in a grid square, the square was only scored once, thereby providing a conservative measure of cheetah concentration.

Cheetah sightings were separated according to whether they were of independent adult males or of adult females (these included females on their own and those with cubs). Males were further separated according to whether or not they were resident on a territory. Individually known males were termed residents if they scent-marked frequently in one particular area, or were termed non-residents if they did not repeatedly scent-mark restricted areas (Caro \& Collins, 1986, 1987b).

\section{Results}

\section{Distribution of Thomson's gazelles}

Figs 1 and 2 show the distribution of Thomson's gazelles on the Serengeti Plains over 12 months of the year. During the first 4 months, January-April, gazelles were 

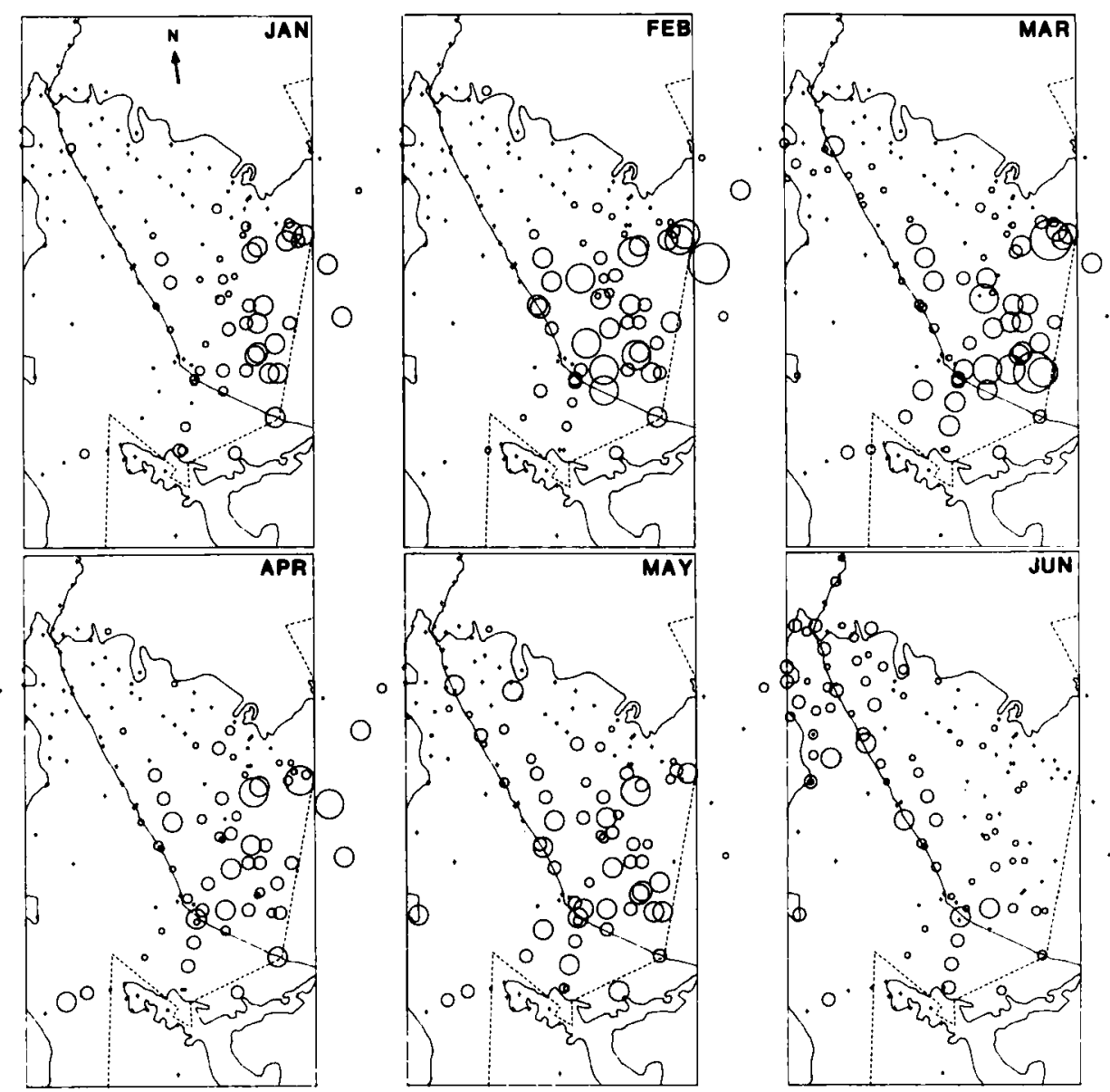

Fig. 1. Abundance of Thomson's gazelles (Gazella thomsoni) at 142 locations on the Serengeti Plains for the months of January to June. Maps $(90 \mathrm{~km}$ by $50 \mathrm{~km})$ show the plains bounded by woodlands in the $\mathrm{N}$ and $\mathrm{W}$, and by the woodland strip of Olduvai gorge in the $\mathrm{S}$ and SE. Park boundary denoted by dashed line; a road (continuous line) runs from NW to SE. Numbers of gazelles were divided into 7 categories: 1-10,11-50, 51$100,101-200,201-500,501-1000,>1000$ and are represented by seven circles increasing in area in proportion to the median number in these categories. Points at which no gazelles were seen are denoted + .

concentrated on the short grass plains near the eastern boundary of the Park although in January many were further east in the Ngorongoro Conservation Area, not shown on the map. During May and June there was a sustained movement of gazelles in a north-westerly direction so that by July gazelles on the plains were concentrated south of Seronera (see Fig. 3 for location) at the junction of the road and northern woodland boundary. Although some gazelles moved into the woodlands from July onwards (TMC and DAC, pers. obs.), where they were not censused, concentrations in the vicinity of Seronera nevertheless remained high until October. During October, however, some animals returned to the short grass plains, and by November most gazelles were found on the plains again; there was a progressive movement eastwards through this region until January.

Fig. 3 shows the direction and significance levels of the Spearman rank-order correlation coefficients of monthly gazelle scans with monthly rainfall at thirty- 

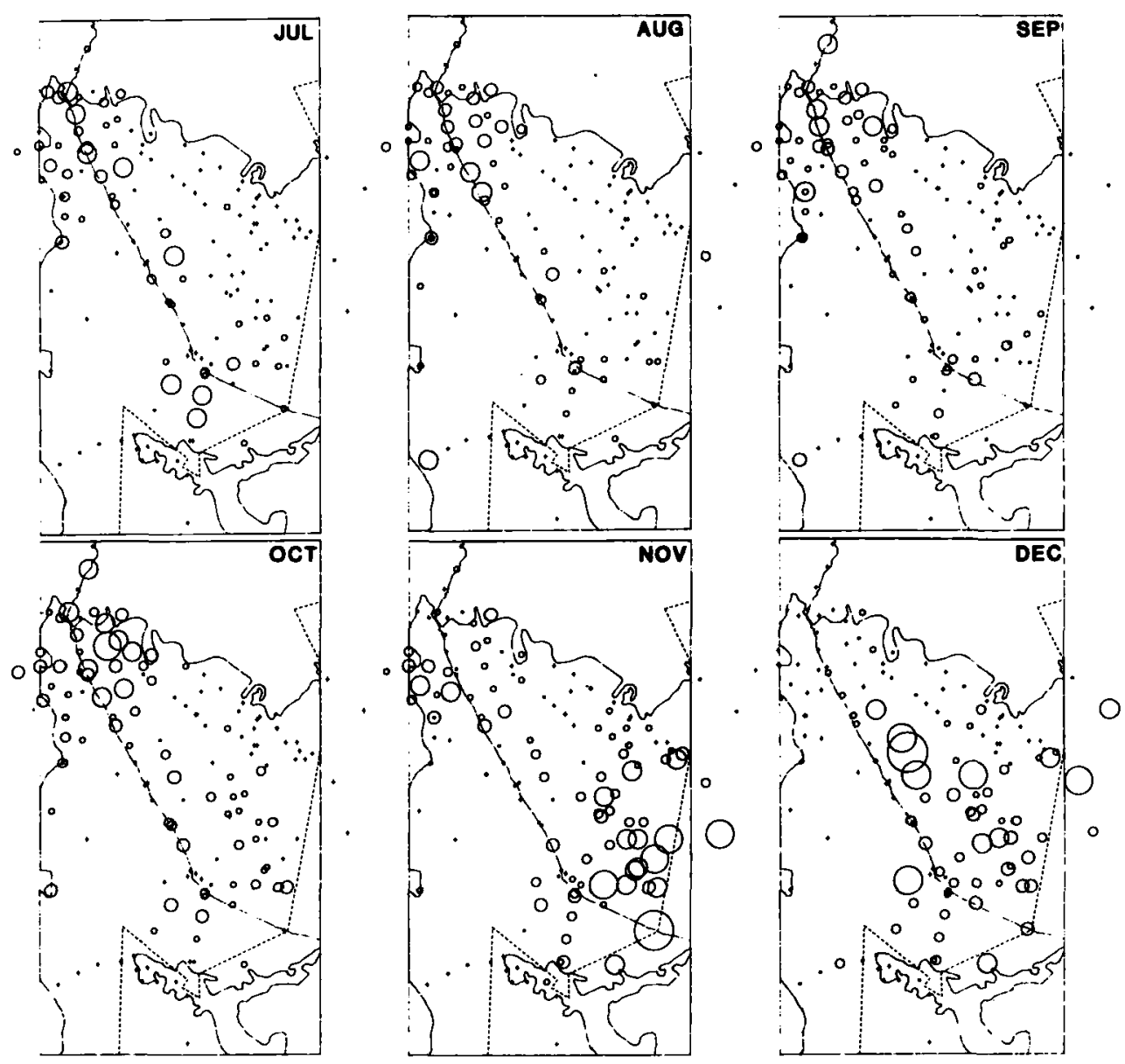

Fig. 2. Abundance of Thomson's gazelles at 142 locations on the Serengeti Plains for the months July to December; see legend to Fig. 1.

three locations on the plains where rain gauges were read (see legend). Categories of gazelles counted were significantly positively correlated with monthly rainfall readings along the eastern border of the Park, in the Ngorongoro Conservation Area to the east of the Park boundary and along the main road, south of 'Naabi south'. To the west of this area, on the central short grass plains near 'Semetu kopjes' and along the main road north of 'Naabi south', gazelle categories were negatively correlated with monthly rainfall although the correlation did not usually achieve significance. These results suggest that gazelle numbers were influenced by rainfall on the eastern plains but not on the central and western plains and woodland border.

\section{Distribution of cheetahs}

Female cheetahs are known to move long distances on the Serengeti Plains (Frame \& Frame, 1981); for example, some individuals seen at 'Barafu kopjes' were subsequently seen at 'Seronera south' later on in the year approximately $40 \mathrm{~km}$ away. 


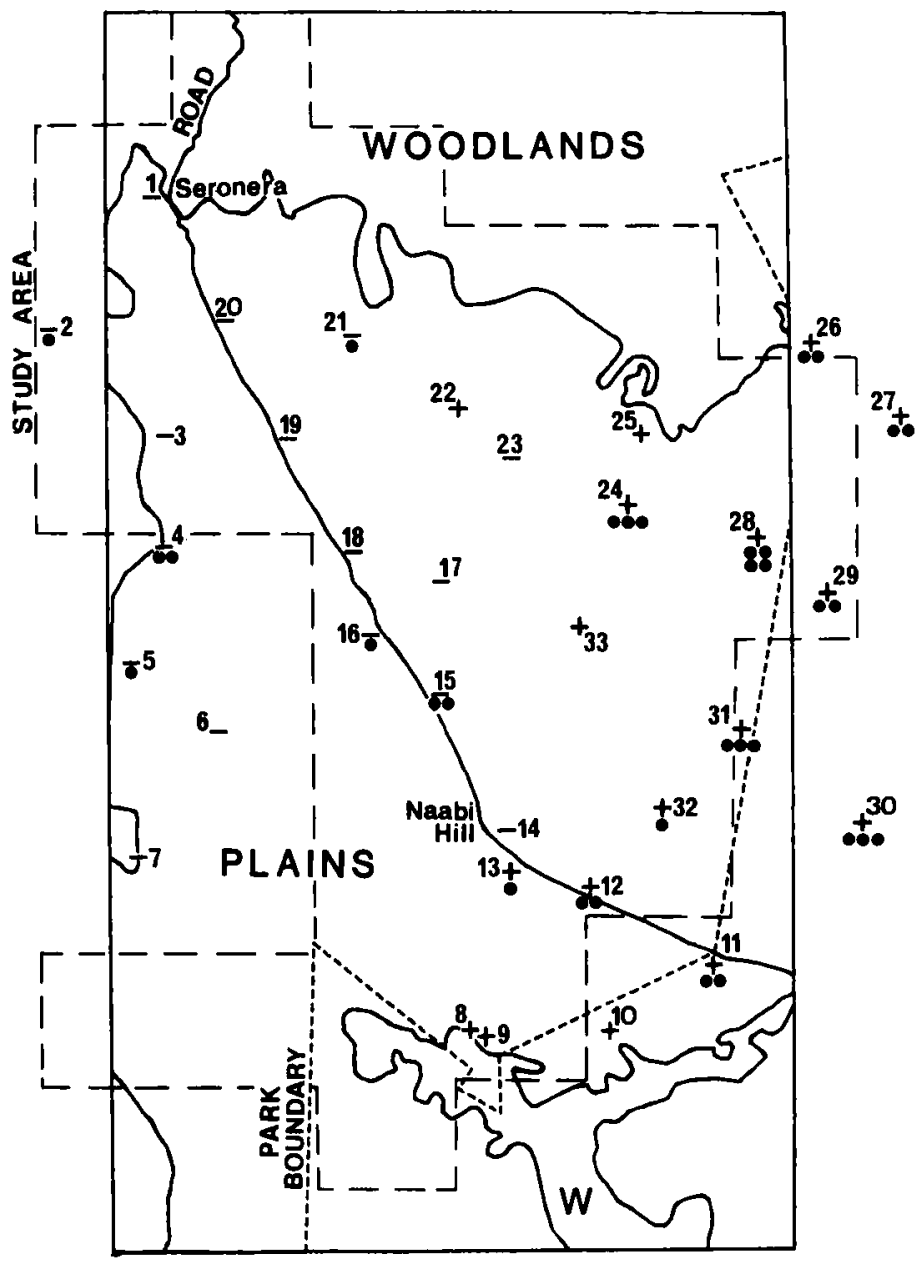

Fig. 3. Position of rain gauges on the Serengeti Plains, + and - denote position of the gauges and also direction of the correlation between monthly rainfall and number of gazelles seen; $\bullet<<0 \cdot 1, \bullet \bullet P<0.05$, - ๑ $P<0.01$, ๑๑९ $P<0.001$. (1) Nyaraswiga $n=25, r_{\mathrm{s}}=-0.207$, NS; (2) Mukoma Plain $n=29, r_{\mathrm{s}}=$ $-0.360, P=0.055$; (3) Rongai $n=28, r_{\mathrm{s}}=-0.048$, NS; (4) Lake Magadi $n=29, r_{\mathrm{s}}=-0.463 ; P=0.012 ;$; (5) Moru kopjes $n=30, r_{\mathrm{s}}=-0.347, P=0.061$; (6) Hidden Valley $n=29, r_{\mathrm{s}}=-0 \cdot 223$, NS; (7) Olbayi $n=29, r_{\mathrm{s}}=$ $-0 \cdot 183$, NS; (8) Ndutu Lodge $n=26, r_{\mathrm{s}}=+0 \cdot 223$, NS; (9) Lake Lagarja $n=29, r_{\mathrm{s}}=+0 \cdot 123$, NS; (10) Ndutu road $n=21, r_{\mathrm{s}}=+0.284$, NS; (11) Naabi south entrance $n=28, r_{\mathrm{s}}=+0.472, P=0.011 ;$ (12) Naabi Naabi Park entrance $n=28, r_{\mathrm{s}}=+0.458, P=0.014$; (13) Naabi south $n=30, r_{\mathrm{s}}=+0.320, P=0.085$; (14) Naabi exclosure $n=29, r_{\mathrm{s}}=-0.078$, NS; (15) Naabi north $n=24, r_{\mathrm{s}}=-0.461, P=0.024$; (16) Simba kopjes (a) $n=$ $27, r_{\mathrm{s}}=-0 \cdot 327, P=0.096$; (17) Simba kopjes (b) $n=23, r_{\mathrm{s}}=-0.080, \mathrm{NS}$; (18) Girtasho $n=27, r_{\mathrm{s}}=-0 \cdot 140$, NS; (19) Seronera-Simba $n=29, r_{\mathrm{s}}=-0 \cdot 261$, NS; (20) Seronera south $n=28, r_{1}=-0 \cdot 224$, NS; (21) Loliondo kopjes $n=30, r_{\mathrm{s}}=-0 \cdot 317, P=0 \cdot 088$; (22) Semetu kopjes (a) $n=24, r_{\mathrm{s}}=+0 \cdot 190$. NS; (23) Semetu kopjes (b) $n=24, r_{\mathrm{s}}=-0.015$, NS: (24) Zebra kopjes $n=30, r_{\mathrm{s}}=+0 \cdot 462, P=0 \cdot 010 ;$ (25) Hoeck's kopje $n=23, r_{\mathrm{s}}=+$ $0 \cdot 267$, NS (gauge faulty); (26) Soit Ayi $n=22, r_{\mathrm{s}}=+0 \cdot 388, P=0 \cdot 037$; (27) Soguna kopjes $n=20, r_{,}=+0 \cdot 383$, $P=0.048$; (28) Barafu kopjes $n=27, r_{\mathrm{s}}=+0.620, P=0.001$; (29) Lemuta North West $n=24, r_{\mathrm{s}}=+0.457$, $P=0.025$; (30) Eland kopjes $n=20, r_{\mathrm{s}}=+0.589, P=0.006$; (31) Merua kopje $n=27, r_{\mathrm{s}}=+0.577, P=0.002$; (32) South East kopjes $n=30, r_{\mathrm{s}}=+0 \cdot 354, P=0.055$; (33) Gol kopjes $n=30, r_{\mathrm{s}}=+0 \cdot 133$, NS. Dashed line shows approximate area in which observers searched for cheetahs; dotted line the Park boundary. 

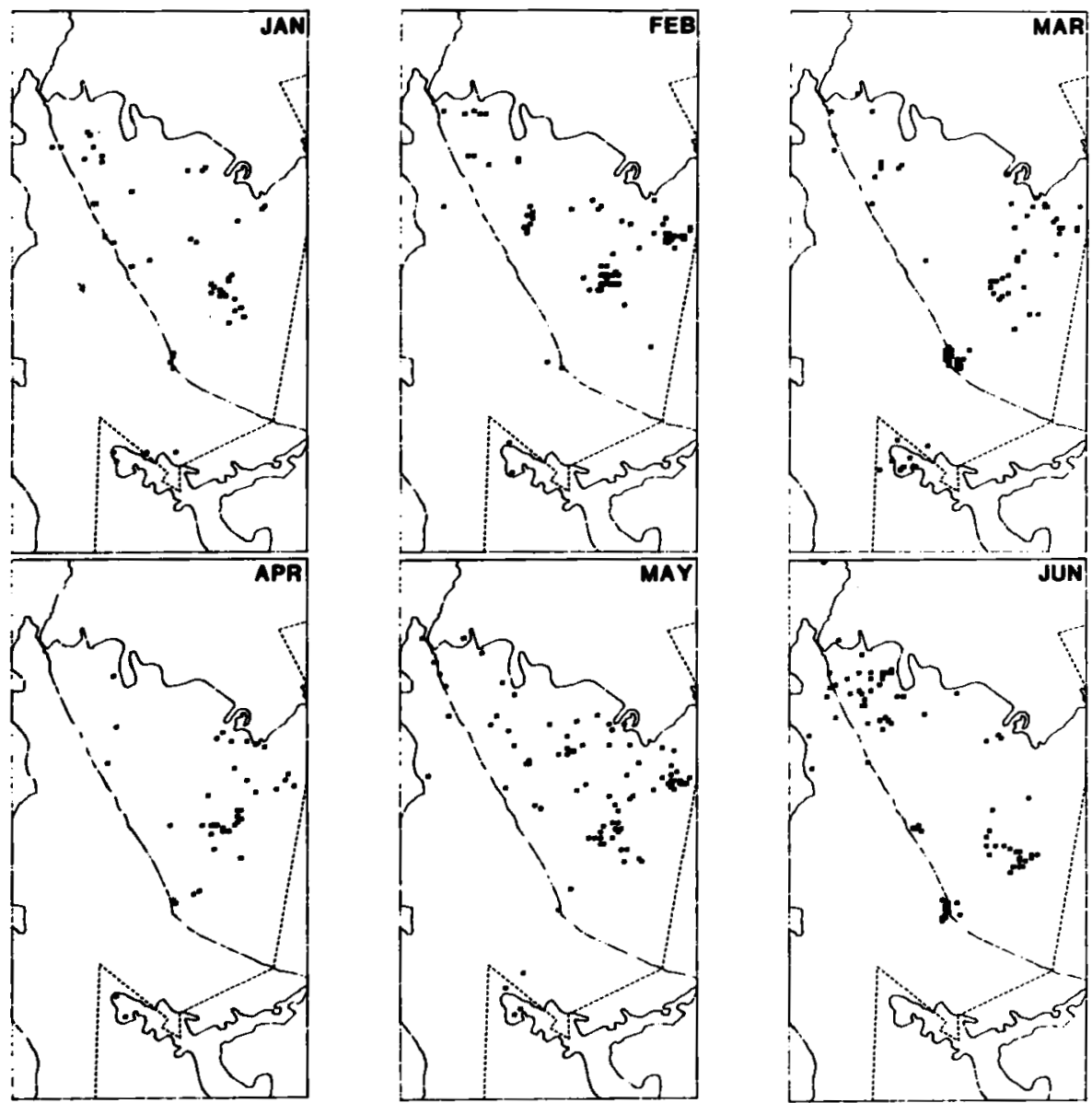

Fig. 4. Distribution of $500 \mathrm{~m} \times 500 \mathrm{~m}$ grid squares in which one or more female cheetahs were sighted for the months January to June. See Fig. 1 for details of the map and Fig. 3 for limits of the study area.

Figs 4 and 5 show the grid squares in which females were seen during each month of the year taken from sightings between February 1982 and July 1985. The distribution of these grid squares corresponded closely with gazelle concentrations on the plains, females being found on the eastern plains in February, March and April but increasingly on the central plains in May. By July, most female cheetahs in the study area had moved north-west, many of them remaining on the woodland edge until November, although some moved on into the woodlands over the course of the dry season (TMC, pers. obs.). In November and December, female cheetahs returned to the short grass plains, thus paralleling the gazelle movements. The correspondence in the distributions of gazelles and female cheetahs over wet and dry seasons is shown in Fig. 6.

Similarly, non-resident male cheetahs were more commonly seen on the plains in the wet season, and around the Seronera area in the dry season, although the number of grid squares in which they were seen was fewer than it was for female cheetahs (Fig. 6). 

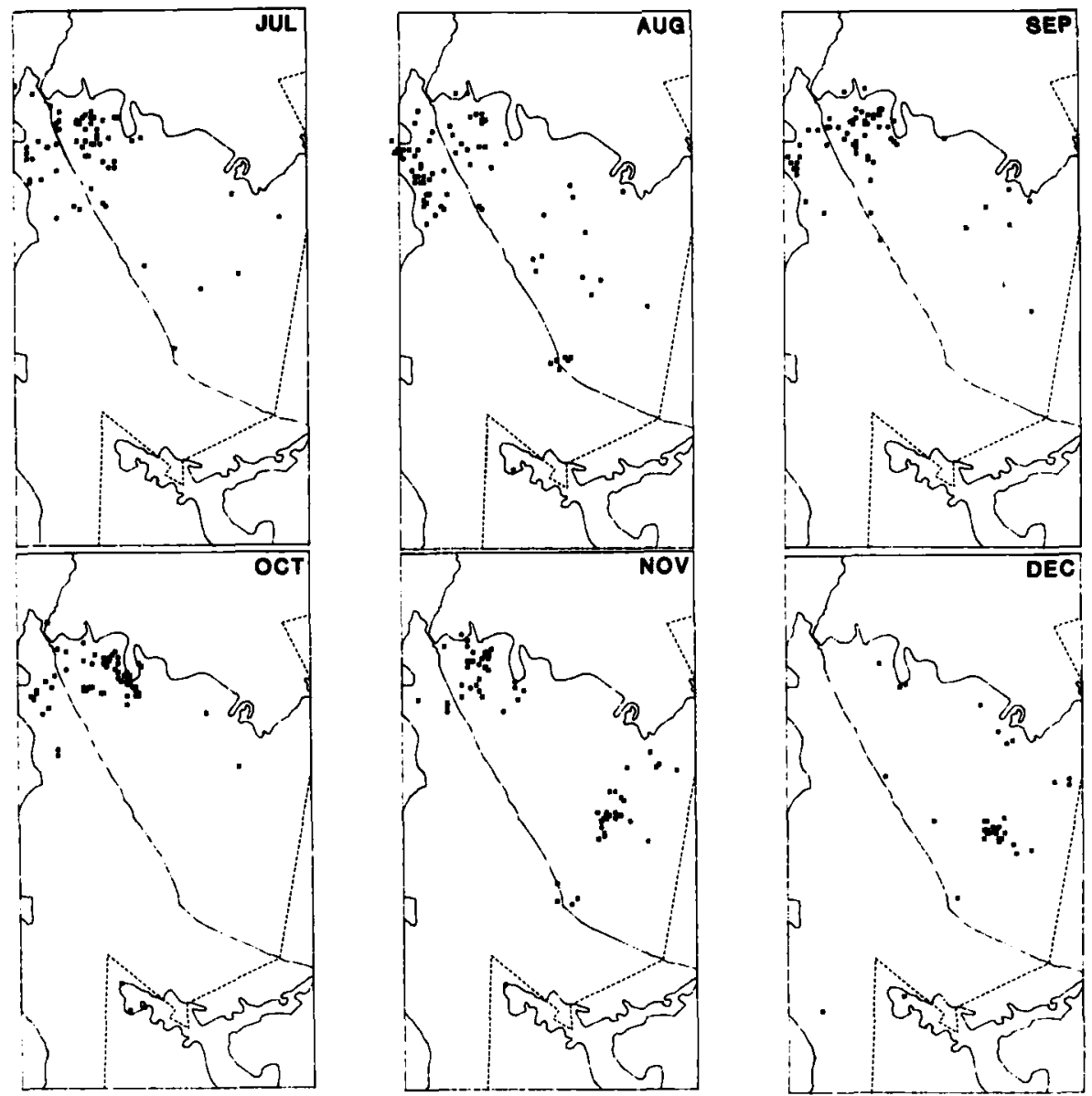

Fig. 5. Distribution of $500 \mathrm{~m} \times 500 \mathrm{~m}$ grid squares in which one or more female cheetahs were sighted for the months July to December.

In contrast, resident male cheetahs did not move to the same degree between wet and dry seasons as did non-resident males (Fig. 6). Although some residents temporarily vacated their territories, this rarely occurred in the wet season (one out of a total of ninety-seven wet season sightings), even among males holding territories on the plains-woodland border. In the dry season, there was slightly more movement off territories (nine out of a total of forty-eight dry season sightings), but even males holding territories on the plains tended to remain on them despite the low abundance of gazelles in this area.

\section{DISCUSSION}

Distribution of Thomson's gazelles

In this study Thomson's gazelles were found in large concentrations on the Serengeti Plains in the wet season but moved north-west to the woodland border in the dry season; some remained on the plains throughout the year. Gazelles also moved west in the dry season (TMC and RMA, pers. obs.) but we had insufficient scan locations in this region of the plains to detect the magnitude of this movement, 
FEMALE CHEETAHS

THOMSON'S GAZELLES
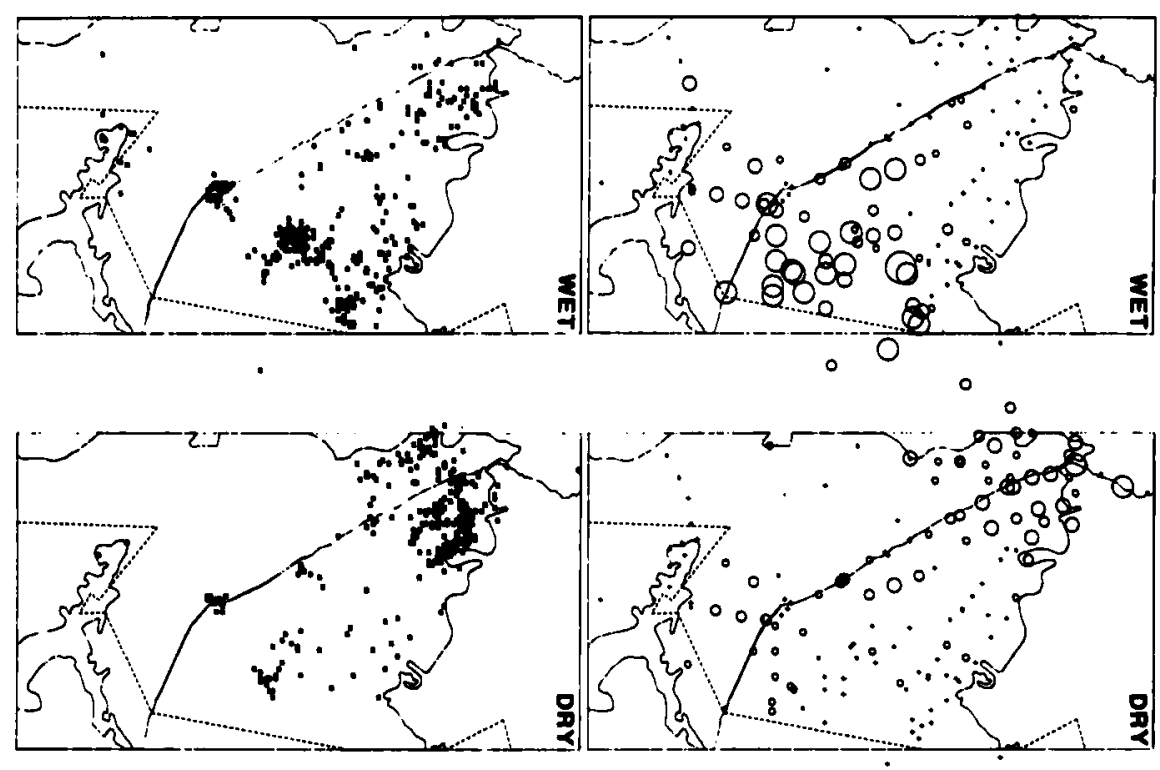

REBIDENT MALES

NON-RESIDENT MALES
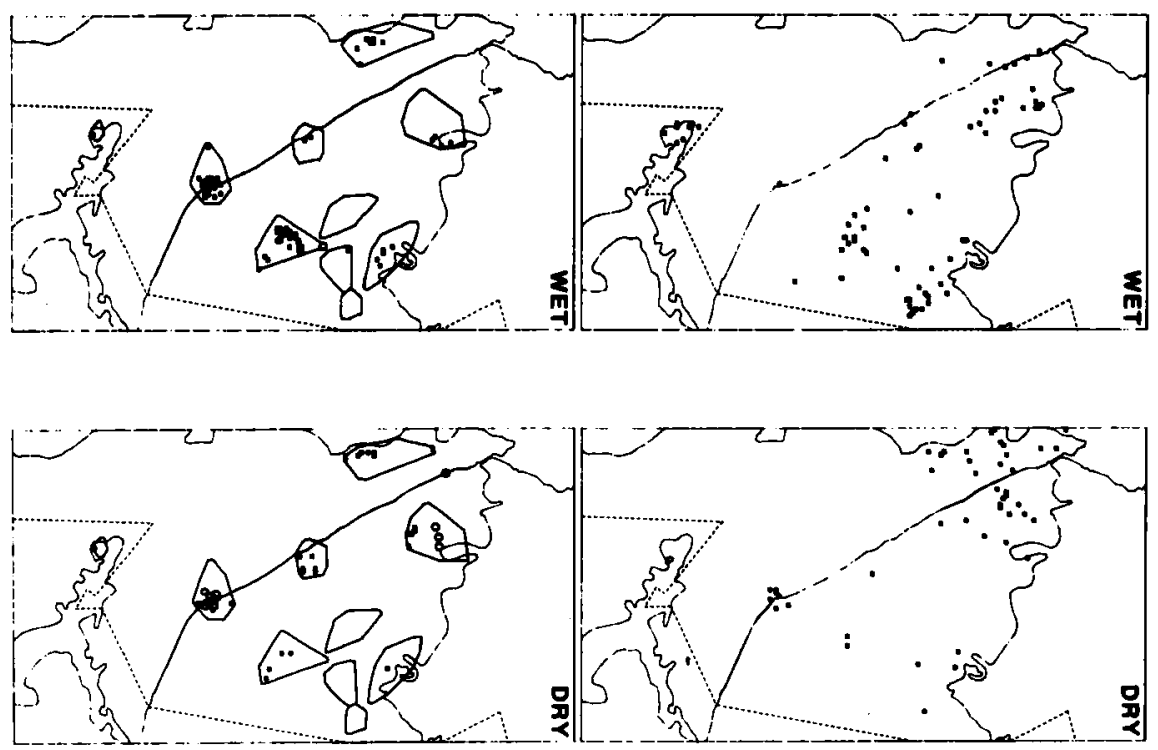

Fig. 6. Abundance of Thomson's gazelles, and distribution of grid squares in which cheetahs were sighted during wet and dry season months. Top right pair of maps: median number of gazelles seen during all wet and all dry season months, see Fig. 1 for key. Remaining three pairs of maps show distribution of $500 \mathrm{~m} \times 500 \mathrm{~m}$ grid squares in which one or more females (bottom left pair), non resident males (top right pair) and resident males (bottom right pair) were seen. On the bottom right pair of maps, male territories, as estimated by minimum polygon method, are superimposed over grid squares in which residents were seen; open circles denote grid squares where residents were seen off their territories. Territory boundaries were larger than total extent of wet and dry season sightings because they were based on sightings starting March 1980, before this study began, and on recording all grid squares that residents were seen to enter after the first sighting of the day. 
nor did we monitor movements of gazelles further into the woodlands. The migration patterns reported here correspond well with data collected in the mid1970s that showed similar seasonal movements of gazelles from the plains to woodland boundary and beyond into the woodlands (Bradley, 1977; Maddock, 1979), and with observations made in the 1960s that showed some gazelles were found on the plains all year round (Schaller, 1972). Bradley (1977) argued that gazelles followed an intermediate level of precipitation tending to avoid wetter woodland areas in the wet season, and the dry short grass plains during the dry season. An unknown proportion of Thomson's gazelles moved into the western corridor to Musabi and Nyamuma Plains (Kruuk, 1972; Maddock, 1979) towards the end of the dry season (September and October) but these movements were not monitored in this study.

As reported here, Thomson's gazelle numbers on the eastern plains were associated with the amount of rainfall suggesting that gazelles were primarily moving there so as to feed on the new grass shoots that quickly appeared in response to rain. McNaughton (1985) noted that both wildebeests, Connochaetes taurinus (Burchell), and Thomson's gazelles arrived on the Serengeti Plains within three days of significant rainfall there. The Thomson's gazelle birth peak occurs during the wet season while they are in this area (Bradley, 1977). Lack of association between rainfall and gazelle numbers in the north and west of the plains suggested that gazelles are unlikely to have moved there in response to growth of new shoots, but for other reasons. Two have been suggested: because they are feeding on high protein dicotyledons which maintain higher dry season levels of protein than grasses (Stelfox \& Hudson, 1986) and which might be made accessible by wildebeests feeding in the same area earlier in the year (Bell, 1971; Maddock, 1979), or because of their need for water (R. Estes, pers. comm.).

As yet there are insufficient data to determine the relative importance of these hypotheses. It is known that primary productivity of grasslands increases in response to grazing by wildebeests which move west and north-west off the plains, and that Thomson's gazelles do collect in areas previously grazed by wildebeests (McNaughton, 1976). Our data showing that few Thomson's gazelles collected along the northern plains border in the dry season are consistent with this hypothesis because relatively few wildebeests left the plains via this route. Clearly, further work is needed on feeding rates and food selectivity of Thomson's gazelles in the dry season.

Turning to the second hypothesis, water is normally present in the Seronera and Mbalageti Rivers along the northern and western boundaries of the plains, respectively, until the end of the dry season and could thus explain why gazelles move into this area. Whether there are sufficient quantities of water in these rivers to sustain the entire Thomson's gazelle population as well as other species throughout the dry season in not known. If there is not, the observed movement of Thomson's gazelles further into the woodlands could be explained, at least in part, because there is more standing water and more dry season rainfall there than on the plains-woodland boundary.

\section{Distribution of cheetahs}

There was a strong correspondence between the areas in which female cheetahs were sighted each month and the numbers of gazelles seen in those areas, as might 
be expected from their diet; for example, $80 \cdot 5 \%(n=174)$ of cheetah mothers' kills throughout the year were of Thomson's gazelles (TMC, unpubl. data). Although cheetah sightings were, to some extent, dependent on which areas were searched by observers, all areas were visited at least once during 25 of the 39 months of the study, in order to count gazelles, and most areas were visited regularly in the remaining 14 months (see also Caro \& Collins, 1987a). Possible bias in observers' search patterns were ameliorated by using the conservative measure of grid squares in which cheetahs were seen rather than weighting squares according to number of cheetahs seen in each square.

There were two exceptions to the correspondence of migration patterns of female cheetahs and gazelles. Despite an abundance of gazelles south-east of ' $\mathrm{Gol}$ kopjes' or south of 'Naabi Hill' in the wet season, few female cheetahs were seen there. Females may have found these areas inhospitable because they were devoid of cover, which reduced the possibilities of both hunting successfully and finding shade (Caro \& Collins, 1987a; FitzGibbon, unpubl. data). Also, some female cheetahs were found near Seronera in the wet season (e.g. in November) though few gazelles remained there; a proportion of these sightings may have represented females in transit from the woodlands out onto the plains.

The two types of males differed in their ranging patterns. Individually identified non-resident males traversed a significantly greater number of grid squares per day than did resident males (mean value of the median number of grid squares nonresident $(n=12)$ and resident $(n=18)$ males traversed per day, 1.2 and 0.6 squares, respectively, $t=2.55, P<0.02$, two-tailed; using males sighted three or more times and whose consecutive sightings were less than 100 days apart). Comparison of the grid squares in which non-resident males were seen in wet and dry seasons showed that they closely followed Thomson's gazelle movements, or the movements of female cheetahs. Non-residents moved through residents' territories but it is not yet known whether they tried to avoid these areas or crossed through them quickly.

In contrast, resident males were found on their territories for most of the yeareven when gazelle abundance was low-although the occasional forays that were made from their territories did occur in months when few Thomson's gazelles were present (Caro \& Collins, 1987a). As a corollary of this, resident males killed and attempted to capture a greater percentage of prey other than Thomson's gazelles than did non-resident males in the dry season $(46.7 \%, n=60 ; 33.0 \%, n=88$, respectively) when Thomson's gazelles were found in low numbers on the majority of territories (Fig. 6). In addition, residents concentrated more on prey other than Thomson's gazelles (usually wildebeests) than did non-residents in the wet season as well $(76 \cdot 6 \%, n=141 ; 19 \cdot 1 \%, n=94$, respectively) even when Thomson's gazelles had returned to the Plains' territories.

\section{Acknowledgments}

We thank the Government of Tanzania and Tanzania National Parks for permission to conduct research and the Serengeti Wildlife Research Institute for facilities. The work was supported by the National Geographic Society, the Royal Society, the Scientific and Engineering Research Council, UK, and the Government of Tanzania. We are grateful to members of the Serengeti Wildlife Research Institute, particularly Mvula $\mathrm{S}$. Bruno, for help in reading the rain gauges, and 
to Marcus Borner for his encouragement and generous help in locating radiocollared cheetahs from the air. We also thank Monique Borgerhoff Mulder and Donna Jefferson for helping with reliability estimates, Pat Bateson for providing facilities at Cambridge, Paul Turke and Richard Wrangham for computer space at Michigan, and to a referee for comments on the manuscript.

\section{References}

Bel.L. R.H.V. (1971) A grazing ecosystem in the Serengeti. Sci. Am. 225(1), 86-93.

Borner, M., Fitzgibron, C.D., Borner, Mo., Caro, T.M., Linidsay, W.K., Collins, D.A. \& Holt, M.E. (1987) The decline in the Serengeti Thomson's gazelle population. Oecologia 73, 32-40.

BradLeY, R.M. (1977) Aspects of the Ecology of the Thomson's Gazelle in the Serengeti National Park, Tanzania. PhD thesis, Texas A \& M University.

Caro, T.M. \& Collins, D.A. (1986) Male cheetahs of the Serengeti. Nat. Geog. Res 2, 7586.

Caro, T.M. \& Collins, D.A. (1987a) Ecological characteristics of territories of male cheetahs (Acinonyx jubatus). J. Zool. 221, 89-105.

Caro, T.M. \& Collins, D.A. (1987b) Male cheetah social organization and territoriality. Ethology 74 , $52-64$.

Frame, G. \& Frame, L. (1981) Swift and Enduring: Cheetahs and Wild Dogs of the Serengeti. E.P. Dutton, New York.

Grzimek, M. \& Grzimek, B. (1960) A study of the game of the Serengeti Plains. Z. Saugetierk. 25, 1-61.

KrUUk, H. (1972) The Spotted Hyaena. University of Chicago Press, Chicago.

KruUK, H. \& TURner, M. (1967) Comparative notes on predation by lion, leopard, cheetah and wild dog in the Serengeti area, East Africa. Mammalia 31, 1-27.

MadDOCK, L. (1979) The 'migration' and grazing succession. In: Serengeti: Dynamics of an Ecosystem. (Eds A.R.E. Sinclair and M. Norton-Griffiths). University of Chicago Press, Chicago.

McNaughton, S.J. (1976) Serengeti migratory wildebeest: facilitation of energy flow by grazing. Science 191, 92-94.

MCNaughton, S.J. (1985) Ecology of a grazing ecosystem: the Serengeti. Ecol. Monogr. 55, 259294.

MiLls, M.G.L. \& MiLls, M.E.J. (1982) Factors affecting the movement patterns of brown hyaena Hyaena brunnea in the southern Kalahari. S. Afr. J. Wild. Res. 12,111-117.

Norton-Griffiths, M. (1978) Counting Animals. African Wildlife Leadership Foundation, Nairobi, Kenya.

SCHALler, G.B. (1972) The Serengeti Lion. University of Chicago Press, Chicago.

SinClair, A.R.E. \& Norton-Griffiths, M. (1982) Does competition or facilitation regulate migrant ungulate populations in the Serengeti? A test of hypotheses. Oecologia 53, 364-369.

Stelfox, B.J. \& Hudson, R.J. (1986) Body condition of male Thomson's and Grant's gazelle in relation to season and resource use. Afri. J. Ecol. 24, 111-120.

(Manuscript received 24 April 1987; revision accepted 30 January 1988) 